\title{
Integrated Structural Analysis and Life Cycle Assessment of Equivalent Trench-Pipe Systems for Sewerage
}

\author{
Anna Petit-Boix ${ }^{1} \cdot$ Núria Roigé $^{2}$ • Albert de la Fuente ${ }^{2}$ • \\ Pablo Pujadas $^{2} \cdot$ Xavier Gabarrell ${ }^{1,3}$. \\ Joan Rieradevall ${ }^{1,3}$ - Alejandro Josa ${ }^{4,5}$
}

Received: 30 December 2014 / Accepted: 15 December 2015

(C) Springer Science+Business Media Dordrecht 2015

\begin{abstract}
The demand for sanitation infrastructures is increasing due to a rise in the urban population. To meet the need for wastewater collection, the construction of sewer networks must comply with a series of technical parameters that indicate whether a solution is feasible or not. Considering that this construction implies a series of environmental impacts, this study coupled a structural analysis of one linear metre of sewer constructive solutions with their life cycle impacts. Different pipe materials (concrete, polyvinylchloride (PVC) and high-density polyethylene (HDPE)) were combined with different trench designs and their environmental performance was assessed using Life Cycle Assessment (LCA). These solutions complied with technical parameters consisting of traffic loads and pavement conditions, among others. Concrete pipes embedded in granular matter result in fewer environmental impacts, such as Global Warming
\end{abstract}

Electronic supplementary material The online version of this article (doi:10.1007/s11269-015-1214-5) contains supplementary material, which is available to authorized users.

Anna Petit-Boix

anna.petit@uab.cat

1 Sostenipra (ICTA-IRTA-Inèdit; 2014 SGR 1412) Institute of Environmental Science and Technology (ICTA), Universitat Autònoma de Barcelona (UAB), Edifici ICTA-ICP, Carrer de les Columnes, 08193 Barcelona, Bellaterra, Spain

2 Department of Civil and Environmental Engineering, Division of Structures, Materials and Construction Technology, School of Civil Engineering, Universitat Politècnica de Catalunya (UPC-Barcelona Tech), Jordi Girona 1-3, Building C1, 08034 Barcelona, Spain

3 Department of Chemical, Biological and Environmental Engineering, School of Engineering (ETSE), Universitat Autònoma de Barcelona (UAB), Campus of the UAB, Bellaterra (Cerdanyola del Vallès), 08193 Barcelona, Catalonia, Spain

4 Department of Civil and Environmental Engineering, Division of Geotechnical Engineering and Geosciences, School of Civil Engineering, Universitat Politècnica de Catalunya (UPC-Barcelona Tech), Jordi Girona 1-3, Building D2, Barcelona, Spain

5 Institute of Sustainability, Universitat Politècnica de Catalunya (UPC-Barcelona Tech), Jordi Girona 1-3, Building VX, Barcelona, Spain 
Potential or Cumulative Energy Demand. Further, re-using the excavated soil results in up to $80 \%$ of environmental savings with respect to extracting new materials. Concerning traffic loads and pavement conditions, failures in plastic pipes could be avoided if these are embedded in concrete. Moreover, the environmental impacts of this solution are similar to those resulting from the substitution of pipes that do not comply with the mechanical requirements of the construction site. Therefore, proper planning is needed to provide cities with sewers that are resilient to time and external loads and reduce the urban environmental impacts.

Keywords Sewer Pipe $\cdot$ Trench $\cdot$ Construction $\cdot$ LCA $\cdot$ Urban design

\section{Introduction}

In the framework of the urban water cycle, infrastructures have to be properly managed to ensure a good water quality status. Currently, $53 \%$ of the world's population concentrates in urban areas (The World Bank 2014) and by 2050 this figure is expected to increase to $70 \%$ (UN 2012). As a result, the construction of new water-related infrastructures or the expansion of the existing ones will also increase. Although they can be technically feasible, traditional and/or economical strategies tend to be implemented regardless of their environmental effects. This is the case of sewer networks, which mainly consist of a pipe embedded in a trench. This system has the function of transporting wastewater from the households to the wastewater treatment plant, acting as a structural element that interacts with the existing urban structures and facilities (e.g., roads, buildings, etc.). However, choosing larger pipes than needed might reduce the self-cleansing power of the network and result in unnecessary additional costs (Bizier 2007) and environmental impacts. Consequently, there is a need for a rigorous approach that identifies appropriate structural pipe-trench designs that optimize the resource consumption and reduce the environmental impacts.

Pipes for sewerage can be classified according to its constitutive material (e.g., concrete, thermoplastic derivate, steel, vitrified clay) or its relative stiffness (rigid or flexible), the latter being the most accepted in the standards. In this regard, flexible pipes can present deformations higher than $2 \%$ (with respect to the internal diameter) when these are subjected to service loads. Once the pipe is installed, these flexibility leads to a direct interaction between the pipe and the lateral soil, the passive soil pressure being a positive mechanical contribution to the pipe strength (McGrath et al. 1990; Hodges and Enyart 1993; Moser 2001). It is worth noting that the quality of the soil and its compaction level are both relevant factors in terms of the mechanical resistance of flexible pipes. Conversely, rigid pipes exhibit a lesser grade of interaction with the surrounding soil since the global deformations during service are reduced. Therefore, the mechanical performance of this kind of pipes mainly depends on its own strength, which is given by the constitutive material. For these reasons, concrete pipes, reinforced or otherwise, were considered as rigid pipes in this study. In the case of flexible pipes, polyvinylchloride (PVC) and high-density polyethylene (HDPE) were studied.

In terms of design, the ground load to which the pipe is subjected in service regime depends on the type of installation. This is commonly assessed by using the classical theories on rigid (Marston 1930) and flexible pipes (Spangler 1941). The formulations deriving from these theories are broadly accepted in most of the standards that regulate sewerage pipes. Besides, additional mechanical requirements should be fulfilled, e.g., installation conditions, traffic loads and maximum deformations or crack widths in the case of flexible and concrete pipes, 
respectively. In this regard, the design of flexible pipes can be dealt with UNE 53331:1997 and EN 1401-1:2009 in Europe and ASTM D2321 (2014) in the USA, whereas EN 1916:2002 and ASTM C118 (2011) can be used for the design of concrete pipes. Alternatively, based on the previous standards, analytical (Peyvandi et al. 2014) and numerical models (da Silva et al. 2008; de la Fuente et al. 2012; de la Fuente et al. 2013) were developed to determine the optimal design of concrete pipes.

Considering the structural configuration of sewer pipes, much effort was expended in developing new backfill materials (Blanco et al. 2014; Pujadas et al. 2015) and determining the physical parameters involved in the pipeline deterioration, e.g., pipe and bedding material, diameters, external loads, infiltration or root infestation (Davies et al. 2001; Jin et al. 2013). In general, reducing the economic costs of the sewer construction and operation has been a concern for urban planners. Genetic algorithms and linear programming have been widely used to optimize sewer networks considering an intricate of pipe diameters, connections, pumps and slopes (Haghighi and Bakhshipour 2012; Swamee and Sharma 2013).

However, the construction of sewers is associated with resource consumption and generation of environmental impacts. Based on ISO (2006), some studies have applied Life Cycle Assessment to estimate the environmental impacts of sewers from raw material extraction to end-of-life. These studies have especially focused on assessing pipe materials. Generally, concrete is environmentally friendlier than other materials such as PVC or HDPE given its durability and composition (INTRON 1995; Anders and Anders 1997). In the case of the installation stage, there is a lack of data. Venkatesh et al. (2009) conducted the LCA of sewers in Norway and assumed that the contributions of bedding materials to the impacts of the system were insignificant, given that they can be naturally sourced. Nevertheless, in small to medium sized cities, Petit-Boix et al. (2014) determined that trench designs using concrete, sand or a combination of both can account for up to $80 \%$ of the environmental burdens of a sewer.

So far, studies that integrate the structural and environmental dimensions of sewer designs are scarce, although they are necessary and interdependent for a sustainable design. Only in multi-criteria approaches were certain structural factors such as settlement damage or ground collapses combined with environmental, economic and social effects. When comparing different excavation alternatives (e.g., microtunnelling, open cuts and sewer trenches), the Analytic Hierarchy Process proved to be a useful tool in the decision-making framework (Bottero and Peila 2005; Bobylev 2011). Therefore, there is a need for determining the technically feasible sewer configurations that result in an optimization of resources and thus minimize the life cycle environmental impacts of the system.

The main goal of this paper is to define optimal sewer designs that comply with structural requirements and minimize the environmental impacts by combining LCA and mechanical parameters. These designs should be structurally equivalent and can be implemented in different urban configurations regardless of the local tradition and economic costs. To achieve this goal, the specific objectives are: (1) to conduct a parametric analysis involving the variables that are relevant for the design of both rigid and flexible pipes; (2) to elaborate an inventory of the material and energy flows required to make up the different trench - pipe systems analyzed; (3) to calculate, evaluate and compare the environmental impacts of a set of constructive solutions using LCA; (4) to assess the effect of varying external conditions on the environmental burdens of sewer pipes, i.e., traffic loads and pavement degradation. 


\section{Material and Methods}

This section describes the integrated methodology applied for determining environmentally optimal designs from a pool of structurally equivalent configurations (Fig. 1). Among the four stages of LCA (ISO 2006) (i.e., goal \& scope, life cycle inventory, life cycle impact assessment and interpretation), the structural analysis was embedded after the definition of the functional unit (FU) in order to enable the definition of the system boundaries.

\subsection{Functional Unit (FU)}

The FU of this analysis is 1 linear metre of sewer pipe with different alternative materials (concrete, PVC or HDPE) and standard diameters of 300, 500 and $1000 \mathrm{~mm}$, which serve to transport $0.072,0.282$ and $1.791 \mathrm{~m}^{3} / \mathrm{s}$ of wastewater, respectively. These flows were calculated using average Manning's roughness coefficients for plastic $(0.010-0.016)$ and concrete pipes (0.008-0.010) (Twort et al. 2000). Of the flows obtained with the Manning's equation, the values selected were the minimum flows that could be transported by both pipe materials.

\subsection{Structural Analysis of Buried Pipes}

With the aim of assessing the influence of each of the mechanical parameters involved in the design of both flexible and rigid pipes, a parametric analysis was carried out considering UNE 53331:1997 and EN 1916:2002 as references, respectively. In this regard, the parameters considered are represented in Supplementary Material 1, e.g., the pipe diameter (outer (OD) and internal (ID) diameters for flexible and rigid pipes, respectively) and thickness (e=(ODID)/2), as well as both the native and backfill soil types.

Regarding the mechanical parameters of the soil, the Standard Proctor (SP) test and the internal friction angle $(\rho)$ were considered as representative of its structural behaviour. On the one hand, the SP factor consists of an indirect magnitude of the soil's density level and, thus, a

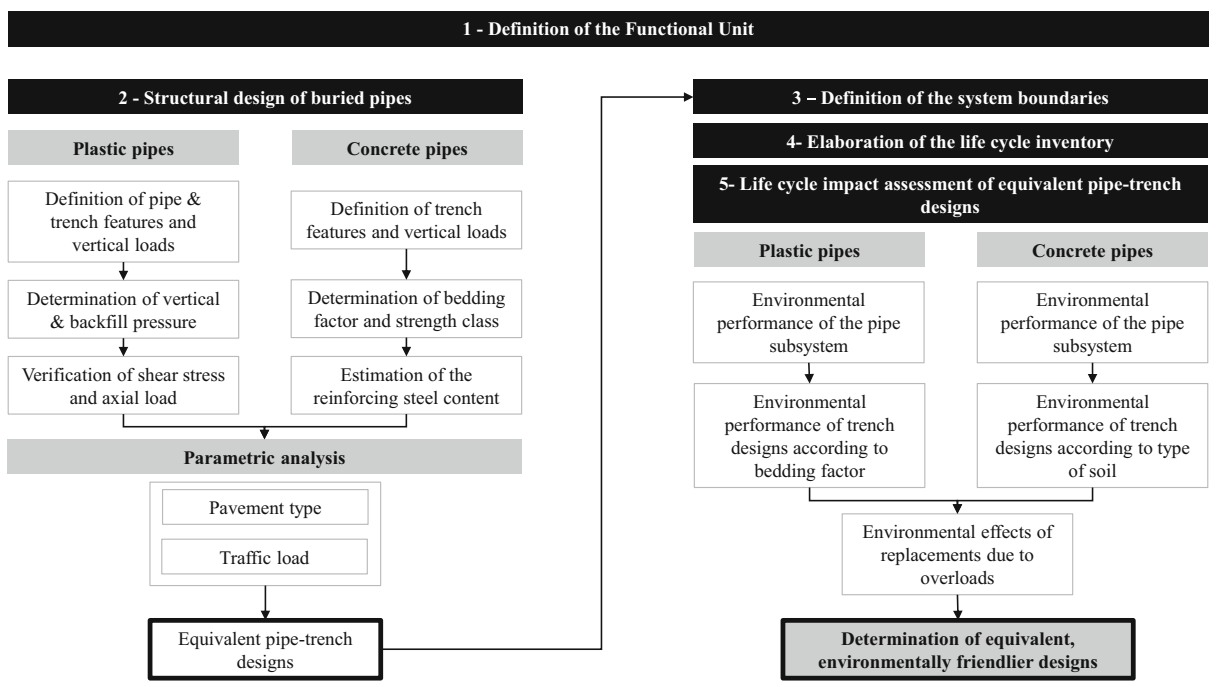

Fig. 1 Methodology for determining optimal sewer designs from a structural and environmental perspective 
reliable parameter to determine its stress bearing and redistributing capacities for each internal friction angle. The standard UNE 53331:1997 recommends the use of SP values ranging from 85 to $100 \%(90,92,95$ and $97 \%)$. For this research, both extreme values were adopted. On the other hand, $\rho$ is related to the soil's shear resistance and this is a result of the MohrCoulomb failure criterion. In the case of concrete pipes, there are 11 possible trench configurations with granular or concrete beddings with different bedding factor (BF) and SP (Supplementary Material 2). The strength class determines the need for reinforcing steel in the pipe structure.

The $\rho$ magnitudes depend on the soil types; UNE 53331:1997 proposes reference values which depend on various physical and geometrical properties of the constitutive particles of the soil (Supplementary Material 3). Axis of 0, 120, 260, 390 and $600 \mathrm{kN}$ represent the traffic loads. These loads could be applied through a pavement system consisting of two common sidewalk or low volume structural layers ( $4 \mathrm{~cm}$ asphalt $+15 \mathrm{~cm}$ concrete slab) or directly over the backfill (without pavement). This last configuration might also simulate a load situation during the construction or maintenance phase (no pavement effect) or even a degradation of the pavement due to cracking or deterioration.

Table 1 gathers the results of the structural design in terms of the required pipe thickness $(e)$ for each case, diameter, pavement configuration and traffic load. Five cases were considered: Case 1 (concrete pipe), Case 2 (PVC pipe), Case 3 (PVC pipe + concrete bedding), Case 4 (HDPE pipe) and Case 5 (HDPE pipe + concrete bedding). Cases 3 and 5 are representative of an increasingly common trend in urban sewer construction that consists of reinforcing the flexible pipe (with approximately the same thickness of the equivalent concrete pipe) with a concrete bedding, to guarantee the stability of the system during construction. This is often adopted since unexpected overloads are likely to occur during construction or maintenance mainly due to the spaces in which the compaction and excavation machines operate.

In environmental terms, Cases 3 and 5 become interesting. Both should present higher environmental impacts and initial costs in comparison with the rest of alternatives. However, they could be attractive in those cases where maintenance is expected during the service life due to superficial structural issues. In this sense, the pipe thickness increases in some cases when plastic pipes must comply with the structural requirements of an area under construction or with a degraded pavement and repositioning might be needed. Therefore, constructing a trench with concrete bedding can prevent this event from occurring and the environmental consequences of this design must be assessed.

\subsection{Definition of the System Boundaries}

The life cycle stages included in the study were divided into two main subsystems in order to assess the relative contribution of different alternatives to the environmental impacts of the entire sewer system (Fig. 2). On the one hand, the pipe subsystem accounted for the material and energy flows related to the pipe production and transport to the construction site. On the other hand, the trench subsystem considered the energy and materials required to install the pipe, the material transport to the construction site and the transport and final disposal of the excavated soil. The operation and maintenance stage was excluded from the analysis, given that the electricity required to pump wastewater is very variable depending on the configuration of the city and it is not possible to assign a standard value to one metre of pipe (Petit-Boix et al. 2015). In addition, according to Petit-Boix et al. (2014), the impacts of the diesel used to demolish the infrastructure are negligible and were not addressed. 
A. Petit-Boix et al.

Table 1 Definition of parameters according to the pavement type, pipe diameter and traffic load $(\mathrm{e}=$ thickness)

\begin{tabular}{|c|c|c|c|c|c|c|c|c|c|c|}
\hline & \multirow{3}{*}{$\begin{array}{l}\mathrm{DN} \\
(\mathrm{mm})\end{array}$} & \multirow{3}{*}{$\begin{array}{l}\text { Traffic } \\
(\mathrm{kN})\end{array}$} & \multicolumn{2}{|c|}{ CASE 1} & \multirow{3}{*}{$\begin{array}{l}\text { CASE } 2 \\
\text { PVC** }\end{array}$} & \multicolumn{2}{|c|}{ CASE 3} & \multirow{3}{*}{$\begin{array}{l}\text { CASE } 4 \\
\text { HDPE** }^{* *}\end{array}$} & \multicolumn{2}{|c|}{ CASE 5} \\
\hline & & & \multicolumn{2}{|c|}{ Concrete $^{*}$} & & \multicolumn{2}{|c|}{$\mathrm{PVC}+$ concrete } & & \multicolumn{2}{|c|}{ HDPE + concrete } \\
\hline & & & $\begin{array}{l}\mathrm{e} \\
(\mathrm{mm})\end{array}$ & Class & & $\begin{array}{l}\mathrm{e} \\
(\mathrm{mm})\end{array}$ & $\begin{array}{l}\text { e concrete } \\
(\mathrm{mm})\end{array}$ & & $\begin{array}{l}\mathrm{e} \\
(\mathrm{mm})\end{array}$ & $\begin{array}{l}\text { e concrete } \\
(\mathrm{mm})\end{array}$ \\
\hline \multirow{15}{*}{$\begin{array}{l}\text { With pavement } \\
\qquad(4 \mathrm{~cm} \text { asphalt }+ \\
15 \mathrm{~cm} \text { concrete } \\
\text { slab) }\end{array}$} & 1000 & 0 & 109 & 60 & 24.5 & 24.5 & 109 & 30.6 & 24.5 & 109 \\
\hline & & 120 & & & & & & 38.2 & & \\
\hline & & 260 & & & & & & 47.7 & & \\
\hline & & 390 & & & & & & & & \\
\hline & & 600 & & 90 & 30.6 & & & 56.6 & & \\
\hline & 500 & 00 & 67 & 60 & 12.3 & 12.3 & 67 & 12.3 & 12.3 & 67 \\
\hline & & 120 & & & & & & 19.1 & & \\
\hline & & 260 & & & & & & & & \\
\hline & & 390 & & & & & & 23.9 & & \\
\hline & & 600 & & 90 & 15.3 & & & 29.7 & & \\
\hline & 300 & 0 & 50 & 60 & 7.6 & 7.6 & 50 & 7.6 & 7.6 & 50 \\
\hline & & 120 & & & & & & 9.56 & & \\
\hline & & 260 & & & & & & 11.92 & & \\
\hline & & 390 & & & & & & 14.79 & & \\
\hline & & 600 & & 90 & 9.56 & & & & & \\
\hline \multirow{15}{*}{$\begin{array}{l}\text { No pavement } \\
(0 \mathrm{~cm} \text { asphalt }+ \\
0 \mathrm{~cm} \text { concrete } \\
\text { slab })\end{array}$} & 1000 & 0 & 109 & 60 & 24.5 & 24.5 & 109 & 30.6 & 24.5 & 109 \\
\hline & & 120 & & 90 & 30.6 & & & 56.6 & & \\
\hline & & 260 & & & & & & & & \\
\hline & & 390 & & & & & & & & \\
\hline & & 600 & & 135 & - & & & - & & \\
\hline & 500 & 0 & 67 & 60 & 12.3 & 12.3 & 67 & 12.3 & 12.3 & 67 \\
\hline & & 120 & & 90 & 15.3 & & & 23.9 & & \\
\hline & & 260 & & & 19.1 & & & 29.7 & & \\
\hline & & 390 & & & & & & & & \\
\hline & & 600 & & 135 & & & & 36.8 & & \\
\hline & 300 & 0 & 50 & 60 & 7.6 & 7.6 & 50 & 7.6 & 7.6 & 50 \\
\hline & & 120 & & 90 & 9.56 & & & 14.79 & & \\
\hline & & 260 & & & & & & 18.43 & & \\
\hline & & 390 & & & & & & & & \\
\hline & & 600 & & 135 & 11.92 & & & 22.86 & & \\
\hline
\end{tabular}

*Bedding factor $(\mathrm{BF})=1.1 * *$ Applicable when the excavated soil belongs to Group 2 and the backfill to Group 1 or 2

Given the nature of the pipe materials, the lifespan of the infrastructure is a critical factor in the environmental assessment. Generally, concrete pipes have a maximum reported service life of 100 years (U.S. Army Corps of Engineers 1998; CPSA 2010), whereas 50 years are attributed to plastics (UNE 53331:1997). In this case, 50 years were considered for both materials in order to address the changes in equivalent trench configurations regardless of the service life. However, a sensitivity analysis was conducted to determine the effect of the lifespan on the environmental impacts of the pipe subsystem. 


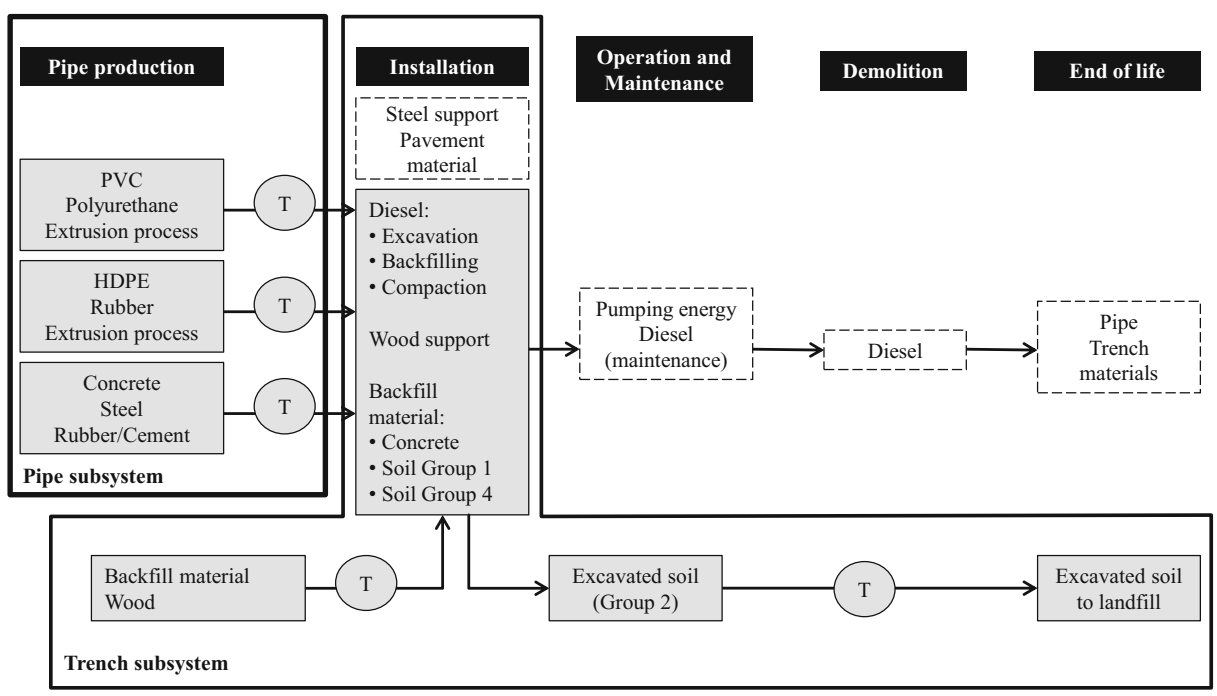

Included \begin{tabular}{ccc}
0 & \\
\hline & Excluded & Transport
\end{tabular}

Fig. 2 Diagram of the system under analysis divided into the pipe and trench subsystems

\subsection{Life Cycle Inventory}

The structural analysis (Section 2.2) provided the technically feasible designs that comply with the minimum mechanical requirements established by the standards. Cases 1, 2 and 4 presented in Table 1 for concrete, PVC and HDPE pipes, respectively, were analyzed considering different traffic loads $(0,260$ and $600 \mathrm{kN})$ and an existing pavement layer. In the case of concrete pipes, the 11 existing trench configurations were compared. A priori the most environmentally optimal solution was $\mathrm{BF}=1.1$ (granular beddings), which has the most basic structural configuration. In this sense, it should be noted that BFs up to 4.0 can be used according to the standard -fulfilling the minimum mechanical requirements but with different stress-strain behaviour-, but the higher the BF, the higher the expected environmental impacts.

When dealing with plastic pipes, BF is not defined and only granular beddings are used. Hence, comparisons were made between trench designs consisting of different types of soil, i.e., native or newly extracted. It was assumed that the excavated native soil belonged to Group 2 (43\% sand, $43 \%$ gravel, $15 \%$ clay), whereas the backfilling soil could be Group 1 (48 \% sand, $48 \%$ gravel, $5 \%$ clay) or 2, having the former a greater quality than the latter and with a composition defined in UNE 53331:1997. Therefore, when the excavation and backfill consisted of the same soil typology, only the diesel consumed in the civil works was accounted for. In contrast, backfilling with high-quality materials implies additional flows related to the material extraction, transport and disposal.

Regarding data sources, besides relying on the volumes provided by the structural analysis to compose the inventory of the pipe subsystem (Supplementary Material 4), data on the diesel consumption to excavate, compact and backfill were retrieved from the MetaBase ITeC (2010). In all cases, wood beams and wood struts used during the installation to retain the excavated soil were re-used 3 and 10 times, respectively (MetaBase ITeC 2010). Steel supports were excluded from the analysis given that they can be re-used many times. With respect to the transport to the construction 
site, an average of $30 \mathrm{~km}$ was considered for local materials (e.g., concrete, cement, soil, etc.) whereas plastics and metals covered a distance of $100 \mathrm{~km}$ by EURO 5 lorry (Mendoza et al. 2012; Petit-Boix et al. 2014; Sanjuan-Delmás et al. 2014). It was also assumed that the excavated soil was transported to a landfill located $10 \mathrm{~km}$ away from the construction site. The ecoinvent database 2.2 (Swiss Centre for Life Cycle Inventories 2009) was used for retrieving background data on the life cycle of the materials and processes involved in the analysis.

\subsection{Life Cycle Impact Assessment}

The environmental impacts of each design were obtained at the life cycle impact assessment stage. It was performed using the SimaPro 7.2.0 software (PRé Consultants 2010) through the classification and characterization steps defined by ISO (2006). The CML IA method (Guinée et al. 2002) and the Cumulative Energy Demand V1.08 (CED) (Hischier et al. 2010) were applied. The impact categories selected were Abiotic Depletion Potential (ADP; kg Sb equivalents), Acidification Potential (AP; $\mathrm{kg} \mathrm{SO}_{2}$ equivalents), Eutrophication Potential (EP; $\mathrm{kg} \mathrm{PO}_{4}{ }^{3-}$ equivalents), Global Warming Potential (GWP; kg $\mathrm{CO}_{2}$ equivalents), Ozone Depletion Potential (ODP; kg CFC-11 equivalents), Human Toxicity Potential (HTP, kg 1.4-DB equivalents) and Photochemical Ozone Creation Potential (POCP; $\mathrm{kg} \mathrm{C}_{2} \mathrm{H}_{4}$ equivalents).

\section{Results}

In this section, the environmental performance of concrete and plastic pipes is presented in Sections 3.1 and 3.2, respectively, and a comparison of the best designs is provided in Section 3.3. A sensitivity analysis was performed (Section 3.4) for assessing the effect of lifespan.

\subsection{Environmental Assessment of Concrete Pipes}

In the analysis of concrete pipes, constructive solutions with BFs ranging between 1.1 and 4.0 were compared (Table 2). Only results for a diameter of $1000 \mathrm{~mm}$ are shown, given that all diameters exhibited approximately the same trends in concrete pipes. Moreover, competition between plastic and concrete pipes is more intense for this diameter (Viñolas 2011).

All designs carry out the same function and are able to protect the pipe from external agents, but $\mathrm{BF}=1.1$ results in lower environmental impacts than the other designs. Implementing this solution results in 30-57\% environmental savings with respect to $\mathrm{BF}=4.0$, which is the worst option due to the extensive use of concrete bedding. This material represents up to $50 \%$ of the GWP in the trench subsystem (Supplementary Material 5), whereas the use of granulate matter contributes to a maximum of $10 \%$ of the impacts in $\mathrm{BF}=1.1$. In contrast, all configurations $(\mathrm{BF})$ include a thin layer of poor concrete, but it does not imply a big surplus in the impact generation because it has $50 \%$ less cement content.

When the pipe and trench subsystems were compared, the latter generally had a greater contribution to the total impacts of the system. Especially when applying more concrete bedding, the trench subsystem might represent up to $80 \%$ of the environmental burdens. Moreover, the importance of this subsystem increases with a decrease in the pipe diameter, given that less material quantity is required in the pipe production process (Supplementary Material 6). 
Table 2 Total environmental impacts of constructive solutions for concrete pipes with a diameter of $1000 \mathrm{~mm}$

\begin{tabular}{|c|c|c|c|c|c|c|c|c|c|c|c|}
\hline \multirow[t]{2}{*}{ Impact category } & \multicolumn{11}{|c|}{ Bedding factor (BF) } \\
\hline & 1.1 & 1.5 & 1.7 & 1.9 & 2.0 & 2.1 & 2.2 & 2.3 & 2.8 & 3 & 4 \\
\hline ADP (kg Sb eq.) & 2.0 & 2.1 & 2.2 & 2.2 & 2.4 & 2.3 & 2.4 & 2.5 & 2.6 & 2.6 & 2.7 \\
\hline $\mathrm{AP}\left(\mathrm{kg} \mathrm{SO} \mathrm{S}_{2} \mathrm{eq}\right)$ & 1.2 & 1.3 & 1.4 & 1.4 & 1.5 & 1.5 & 1.5 & 1.6 & 1.7 & 1.6 & 1.8 \\
\hline $\mathrm{EP}\left(\mathrm{kg} \mathrm{PO}_{4}{ }^{3-}\right.$ eq. $\left.\cdot 10^{-1}\right)$ & 3.6 & 3.8 & 4.1 & 4.1 & 4.4 & 4.4 & 4.4 & 4.7 & 4.8 & 4.7 & 5.0 \\
\hline $\operatorname{GWP}\left(\mathrm{kg} \mathrm{CO}_{2} \mathrm{eq} \cdot 10^{+2}\right)$ & 3.4 & 3.5 & 3.7 & 3.7 & 5.0 & 3.9 & 5.1 & 5.1 & 5.3 & 5.7 & 5.8 \\
\hline ODP (kg CFC-11 eq. $\cdot 10^{-5}$ ) & 3.7 & 3.8 & 4.1 & 4.1 & 4.4 & 4.2 & 4.4 & 4.6 & 4.7 & 4.6 & 4.8 \\
\hline HTP $\left(\mathrm{kg} 1,4-\mathrm{DB}\right.$ eq. $\left.\cdot 10^{+2}\right)$ & 1.4 & 1.5 & 1.6 & 1.6 & 1.7 & 1.8 & 1.7 & 1.8 & 1.8 & 1.8 & 1.9 \\
\hline PCOP $\left(\mathrm{kg} \mathrm{C}_{2} \mathrm{H}_{4} \mathrm{eq} \cdot 10^{-2}\right)$ & 5.4 & 5.6 & 6.0 & 6.0 & 6.5 & 6.3 & 6.6 & 6.9 & 7.0 & 6.9 & 7.3 \\
\hline $\mathrm{CED}\left(\mathrm{MJ} \cdot 10^{+3}\right)$ & 4.9 & 5.2 & 5.5 & 5.5 & 6.0 & 5.8 & 6.1 & 6.3 & 6.4 & 6.4 & 6.7 \\
\hline
\end{tabular}

\subsection{Environmental Assessment of Plastic Pipes}

When assessing flexible pipes, differences between plastic types were observed. Figure 3 depicts the environmental performance of PVC and HDPE pipes with a diameter of $1000 \mathrm{~mm}$ when there is a pavement layer. The pipe thicknesses $(e)$ are the ones required for different traffic loads. According to Table 1, in the range of 0-390 kN PVC pipes have the same structural requirements, whereas in the case of HDPE $e$ increases from 30.6 to $47.7 \mathrm{~mm}$. In environmental terms, this means that the impacts of HDPE might become greater than those of PVC when the traffic load increases. Therefore, PVC would generally be a good solution to manage heavier traffic loads using the same quantity of material.

Regarding the trench subsystem, the material and energy requirements are the same in HDPE and PVC pipes. For a constant pipe diameter, there are differences in the total impacts of the system when backfilling materials are concerned (Table 3). In general, re-using the excavated soil as backfill material has important environmental savings (30-80 \%) with respect to applying a transported high-quality soil. The main processes involved in these

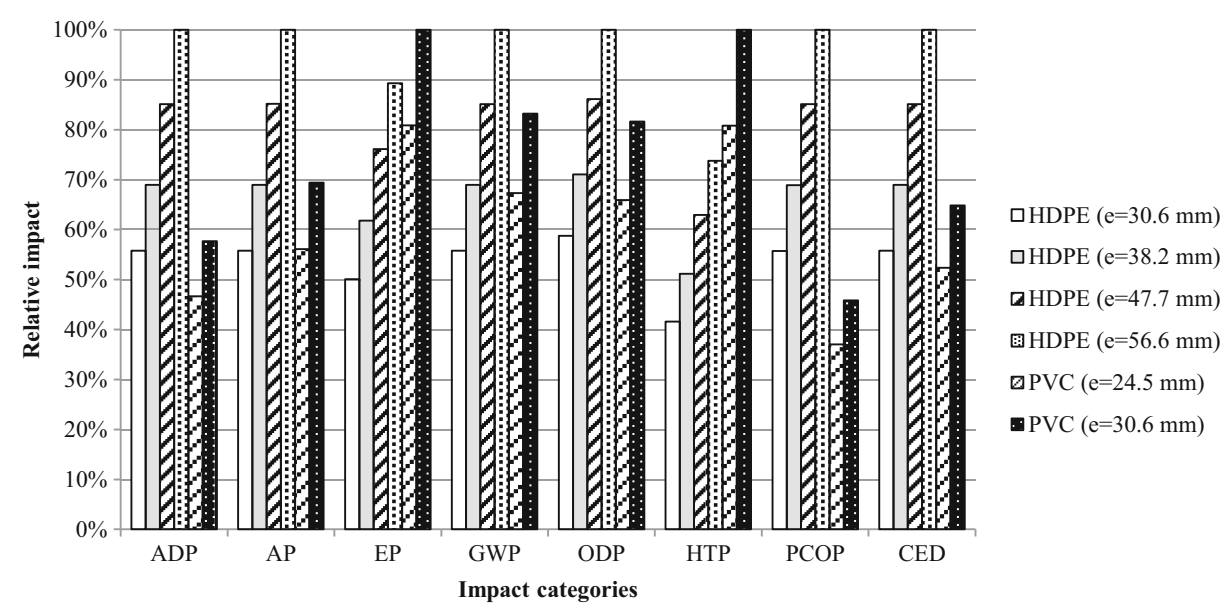

Fig. 3 Comparison of the pipe subsystem of PVC and HDPE with a pipe diameter of $1000 \mathrm{~mm}$, different thicknesses (e) and a pavement layer 
Table 3 Total impact of PVC and HDPE constructive solutions with a pipe diameter of $1000 \mathrm{~mm}$, considering a pavement layer and null traffic load. The type of backfill material is also compared: when the excavated and backfill soil are the same (re-used material) or have a different quality (new material)

\begin{tabular}{|c|c|c|c|c|}
\hline Impact category & $\begin{array}{l}\text { PVC } \\
\text { (re-used material) }\end{array}$ & $\begin{array}{l}\text { PVC } \\
\text { (new material) }\end{array}$ & $\begin{array}{l}\text { HDPE } \\
\text { (re-used material) }\end{array}$ & $\begin{array}{l}\text { HDPE } \\
\text { (new material) }\end{array}$ \\
\hline ADP (kg Sb eq.) & 2.9 & 3.8 & 3.4 & 4.3 \\
\hline $\mathrm{AP}\left(\mathrm{kg} \mathrm{SO} \mathrm{S}_{2} \mathrm{eq}\right)$ & 0.99 & 1.4 & 0.98 & 1.4 \\
\hline $\mathrm{EP}\left(\mathrm{kg} \mathrm{PO}_{4}{ }^{3-}\right.$ eq. $\left.\cdot 10^{-1}\right)$ & 1.8 & 3.0 & 1.3 & 2.5 \\
\hline $\mathrm{GWP}\left(\mathrm{kg} \mathrm{CO} \mathrm{CO}_{2} \mathrm{eq} 10^{+2}\right)$ & 2.7 & 3.7 & 2.3 & 3.3 \\
\hline ODP (kg CFC-11 eq. $\cdot 10^{-5}$ ) & 0.68 & 2.7 & 0.65 & 2.64 \\
\hline HTP (kg 1,4-DB eq. $\left.\cdot 10^{+2}\right)$ & 0.68 & 1.1 & 0.44 & 0.82 \\
\hline PCOP $\left(\mathrm{kg} \mathrm{C} \mathrm{CH}_{4} \mathrm{eq} \cdot 10^{-2}\right)$ & 4.8 & 6.5 & 6.9 & 8.6 \\
\hline $\mathrm{CED}\left(\mathrm{MJ} \cdot 10^{+3}\right)$ & 7.8 & 9.9 & 8.2 & 10 \\
\hline
\end{tabular}

changes are the transport of material and waste to and from the construction site and the landfill disposal, with a contribution of $20-45 \%$ to the trench subsystem.

Similarly to concrete pipes, the influence of the pipe subsystem on the entire system is greater when the soil is re-used. However, the pipe might also contribute with more than $50 \%$ of the impacts in 5 of 8 indicators when new materials are applied (Supplementary Material 7). This highlights the effects of using oil derivatives instead of locally extracted materials as in the case of concrete.

\subsection{Comparison of Equivalent Designs}

Having determined the optimal solutions for concrete $(\mathrm{BF}=1.1)$, PVC and HDPE pipes (reused backfill material), the three designs were compared in a time span of 50 years. In comparison with concrete, plastic pipes become thicker with an increase in the traffic load (Table 1), especially in the case of HDPE. In this sense, equivalent HDPE pipes with a diameter of $1000 \mathrm{~mm}$, for instance, experience a variation in their environmental burdens: $202 \mathrm{~kg}$ of $\mathrm{CO}_{2}$ eq when there is no traffic load $(0 \mathrm{kN})$ and $363 \mathrm{~kg}$ of $\mathrm{CO}_{2}$ eq. when there are $600 \mathrm{kN}$. Moreover, an inexistent or degraded pavement also implies an increase in some cases. Continuing with the example of HDPE, a pipe thickness of $47.7 \mathrm{~mm}$ is required in a load of $260 \mathrm{kN}$ when there is a pavement layer. When there is no pavement, it rises up to $56.6 \mathrm{~mm}$ in order to fulfil an equivalent function. As a result, the environmental impacts vary by $20 \%$ (Fig. 4).

These changes in the thickness requirements must be considered before constructing the sewer. When a plastic pipe with a certain diameter and thickness is installed complying with the mechanical requirements of a paved area, it must be considered that there could be a failure or collapse due to pavement degradation or an increase in the traffic loads. An alternative is to embed it in concrete. In such case, there are no changes in the pipe thickness and the minimum $e$ can be applied because the concrete bedding supports all the external loads. In environmental terms, this situation also leads to different results.

Following the requirements presented in Table 1, it can be noted that there are no changes in the pipe thickness regardless of the presence of the pavement layer. In this case, the environmental impacts of a concrete-bedded trench (Cases 3 and 5) duplicate the ones of granulate systems (Cases 2 and 4) (Fig. 4). However, from 120 to $390 \mathrm{kN}$, pipes need to be thicker when the pavement is degraded. Hence, when a pipe designed for a paved area is affected by disturbances in the road or by soil alterations (e.g., variations in the phreatic level), it might 


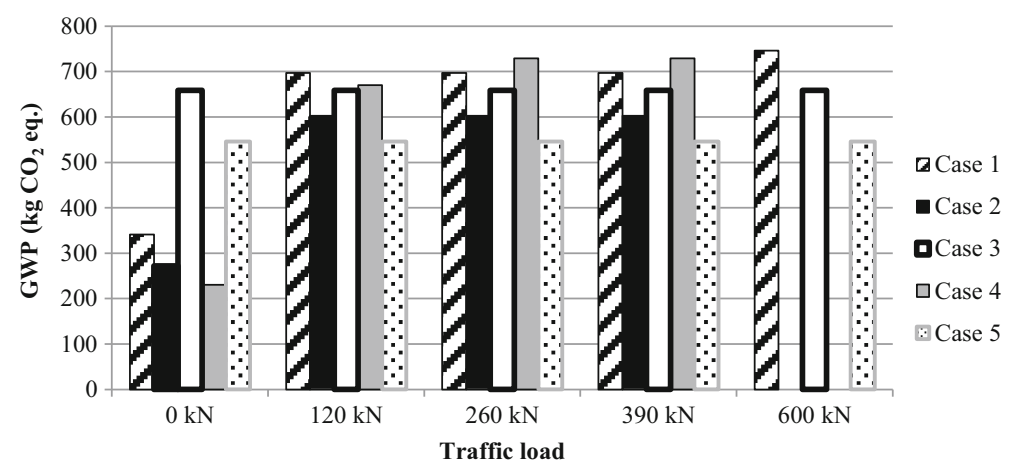

Fig. 4 Comparison of the GWP of concrete pipes (Case 1) and granular (Cases 2 and 4) and concrete-bedded (Cases 3 and 5) solutions for plastics $(1000 \mathrm{~mm})$ considering different traffic loads when the pavement is degraded or inexistent

need to be replaced with a pipe with the proper thickness. In this sense, this reposition results in Cases 2 and 4 having equal or greater environmental impacts than Cases 3 and 5. Finally, Cases 2 and 4 cannot resist a situation with no pavement when the traffic load is $600 \mathrm{kN}$ and, in this case, only a concrete-bedded solution is possible. This does not happen when the pipe diameters are smaller than $1000 \mathrm{~mm}$, which means that the competitiveness of plastics is lower in larger diameters. This is also true when the results are assessed considering the wastewater flow (Supplementary Material 8), which can degrade the internal surface of the pipe. It must be noted that there is also a variation between 0 and $120 \mathrm{kN}$ in concrete pipes (Case 1), but in this case it is due to a change in the strength class. However, the environmental impacts of plastic and concrete pipes become more similar with an increase in the traffic loads.

\subsection{Sensitivity Analysis}

In general, the results obtained in this paper are slightly different from the ones reported in previous analyses, where concrete was presented as an environmentally friendly solution with respect to other sewer pipe materials (INTRON 1995; Anders and Anders 1997; Petit-Boix et al. 2014). In this study, the same lifespan has been attributed to all materials, i.e., 50 years. However, this is a key point when determining their impacts. Therefore, a sensitivity analysis was conducted in which the lifespan of concrete and plastics varied according to the maximum values mentioned in Section 2.3 (Supplementary Material 9). If the impacts obtained in Tables 2 and 3 are attributed to different lifespan scenarios - 50 and 100 years to concrete and 25 and 50 years to plastic in figures 9A.1 and 9A.2, respectively - there are important changes in the annual GWP of each solution. A longer service life results in concrete being the best solution in terms of $\mathrm{CO}_{2}$ eq. emissions per year in the long term, whereas the need for repositioning increments the environmental impacts of plastic pipes in both cases. PVC is the material that presents greater impacts, which diverges from the results obtained by Petit-Boix et al. (2014). The main difference is that a specific structural calculation was conducted in the present analysis whilst the latter relied on generic construction databases.

Nevertheless, when this analysis is made with diameters of 300 and $500 \mathrm{~mm}$ (9B and 9C), the results are similar to those presented in Section 3.3. Here, plastics perform better than concrete both in the short and long term, which results in PVC and HDPE being more competitive materials for the construction of small pipes. 


\section{Discussion}

After determining the most suitable designs for rigid and flexible pipes, there are some relevant features in the design and environmental performance of sewers that should be considered.

In the case of concrete pipes, the same pipe thickness complies with the mechanical requirements of all traffic loads regardless of the pavement system. As a result, there were no differences in the environmental results related to changes in the external loads. In this sense, concrete pipes could be viewed as a resilient system that is able to provide continuity to sanitation services in the long term, even when there are disturbances at the superficial level. Still, the environmental performance could be improved; for instance, the impacts of the cement content could be reduced by changing the production materials and energy sources (Valderrama et al. 2013).

Further, planning is also essential to reduce the urban environmental performance. Especially in areas with intensive anthropogenic activities, envisioning the maintenance and alterations in subterranean facilities from the design and planning stage might help to reduce environmental and economic costs. In addition, in the framework of urban growth, rural or periurban areas might turn into more artificial areas, with the consequent alteration of the land use and drainage requirements. Plastic pipes might be a preferable option for their economic costs, but decision-makers should consider that embedding pipes in concrete might be a better solution because of avoided repositioning needs. The system might have a longer lifespan and when superficial modifications (e.g., in the road) are required, the sewer might remain safe from external damage.

\section{Conclusions}

This analysis embedded the structural analysis of pipe-trench designs in the environmental LCA of this system in order to determine environmentally optimal solutions that could be implemented in any city. Comparing concrete and plastic pipe configurations, urban planners should consider several aspects when deciding on a constructive solution:

- Concrete pipes with a $\mathrm{BF}=1.1$ result in fewer environmental impacts than greater BFs when performing the same function of protecting the pipe from external agents.

- The contribution of the trench to the overall impacts of the sewer system is especially relevant when concrete beddings are applied and can account for up to $80 \%$ of the system burdens.

- Re-using the excavated materials results in significant environmental savings with respect to replacing the native soil with newly extracted materials.

- Considering the same lifespan for all materials, constructing sewer stretches using plastic pipes embedded in concrete can result in better environmental and structural results. Planners should bear in mind that implementing granular beddings for a certain pipe diameter and thickness might result in failures when the pavement conditions worsen due to construction works or deterioration.

- Long-term planning should consider that concrete scores better for larger pipes in a time span of 100 years and that it is resilient to changes in the external loads, whereas plastic pipes are preferable for smaller pipes even when they have a shorter lifespan. 
Acknowledgments The authors would like to thank the Spanish Ministry of Education for the grant awarded to A. Petit-Boix (FPU13/01273) to conduct this research.

\section{References}

Anders K, Anders A (1997) Environmental assessment of sewage pipes in PVC, PE, PP and concrete (Miljøvurdering af afløbsrør i PVC, PE, PP og beton). DOR/Nordiska Plaströrgruppen, Stock

ASTM Standard C118 (2011) Standard Specification for Concrete Pipe for Irrigation or Drainage. doi:10.1520/ C0118-11, www.astm.org

ASTM Standard D2321 (2014) Standard Practice for Underground Installation of Thermoplastic Pipe for Sewers and Other Gravity-Flow Applications. doi:10.1520/D2321-14, www.astm.org

Bizier P (2007) Gravity sanitary sewer design and construction, ASCE 2nd E. ASCE Publications, ASCE Publications

Blanco A, Pujadas P, Cavalaro SHP, Aguado A (2014) Methodology for the design of controlled low-strength materials. Application to the backfill of narrow trenches. Constr Build Mater 72:23-30. doi:10.1016/j. conbuildmat.2014.09.008

Bobylev N (2011) Comparative analysis of environmental impacts of selected underground construction technologies using the analytic network process. Autom Constr 20:1030-1040. doi:10.1016/j.autcon.2011.04.004

Bottero M, Peila D (2005) The use of the analytic hierarchy process for the comparison between microtunnelling and trench excavation. Tunn Undergr Sp Technol 20:501-513. doi:10.1016/j.tust.2005.03.004

CPSA. Concrete Pipeline Systems Association (2010) PAS 2050- partial lifecycle assessment. Cradle-to-gate analysis for concrete pipeline. Manhole Ring and Cover Slab

da Silva JL, El Debs MK, Beck AT (2008) Reliability evaluation of reinforced concrete pipes in crack opening limit state. RIEM 1:314-330

Davies J, Clarke B, Whiter J et al (2001) The structural condition of rigid sewer pipes: a statistical investigation. Urban Water 3:277-286. doi:10.1016/S1462-0758(01)00036-X

de la Fuente A, Escariz RC, de Figueiredo AD, Molins C, Aguado A (2012) A new design method for steel fibre reinforced concrete pipes. Constr Build Mater 30:547-555. doi:10.1016/j.conbuildmat.2011.12.015

De La Fuente A, Escariz RC, De Figueiredo AD, Aguado A (2013) Design of macro-synthetic fibre reinforced concrete pipes. Constr Build Mater 43:523-532. doi:10.1016/j.conbuildmat.2013.02.036

EN 1401-1:2009 Plastic piping systems for non-pressure underground drainage and sewerage. Unplasticized poly(vinyl chloride) (PVC-U). Specifications for pipes, fittings and the system. British Standards Institution

EN 1916:2002 Concrete pipes and fitting, unreinforced, steel fibre and reinforced. AENOR, Madrid

Guinée JB, Gorrée M, Heijungs R, Huppes G, Kleijn R, Koning A de, Oers L van, Wegener Sleeswijk A, Suh S, Udo de Haes HA, Bruijn H de, Duin R van HM (2002) Handbook on life cycle assessment. Operational guide to the ISO standards. I: LCA in perspective. IIa: Guide. IIb: Operational annex. III: Scientific background. Kluwer Academic Publishers, ISBN 1-4020-0228-9, Dordrecht, 692 pp.

Haghighi A, Bakhshipour AE (2012) Optimization of sewer networks using an adaptive genetic algorithm. Water Resour Manag 26:3441-3456. doi:10.1007/s11269-012-0084-3

Hischier R, Weidema B, Althaus $\mathrm{H}$ et al (2010) Implementation of life cycle impact assessment methods. Final report ecoinvent v2.2 No. 3. Swiss Centre for Life Cycle Inventories, Dübendorf

Hodges SH, Enyart JI (1993) Standard installation. International Conference on Pipeline Infrastructure, Texas

INTRON (1995) Environmental profile and environmental measures of a concrete external sewer [Intron report No. 95027] and Environmental profile and environmental measures of an external sewer of PVC and vitrified clay in comparison to concrete [Intron report No. 95195]. INTRON, Netherlands

ISO (2006) ISO 14040: 2006 Environmental management - Life cycle assessment - Principles and framework

Jin NJ, Hwang HG, Yeon JH (2013) Structural analysis and optimum design of GRP pipes based on properties of materials. Constr Build Mater 38:316-326. doi:10.1016/j.conbuildmat.2012.07.115

Marston A (1930) The theory of external loads on closed conduits in the light of the latest experiments. Bulletin 96. Iowa Engineering Experiments Station, Ames

McGrath TJ, Chambers RE, Sharff PA (1990) Recent trends in installation standards for plastic pipe. Buried plastic pipe technology. ASTM STP 1093:281-293

Mendoza J-M, Oliver-Solà J, Gabarrell X, Rieradevall J, Josa A (2012) Planning strategies for promoting environmentally suitable pedestrian pavements in cities. Transp Res Part D: Transp Environ 17:442-450. doi:10.1016/j.trd.2012.05.008

MetaBase ITeC (2010) Online ITeC database: prices, technical details, companies, certificates, product pictures and environmental data. http://www.itec.cat/metabase. Accessed Feb 2013

Moser AP (2001) Buried plastic pipe technology, issue 1093. ASTM International 
Petit-Boix A, Sanjuan-Delmás D, Gasol C et al (2014) Environmental assessment of sewer construction in small to medium sized cities using life cycle assessment. Water Resour Manag 28:979-997. doi:10.1007/s11269014-0528-Z

Petit-Boix A, Sanjuan-Delmás D, Chenel S et al (2015) Assessing the energetic and environmental impacts of the operation and maintenance of Spanish sewer networks from a life-cycle perspective. Water Resour Manag 29:2581-2597. doi:10.1007/s11269-015-0958-2

Peyvandi A, Soroushian P, Jahangirnejad S (2014) Structural design methodologies for concrete pipes with steel and synthetic fiber reinforcement. ACI Struct J 111:83-91

PRé Consultants (2010) SimaPro 7.2.0. PRé Consultants, Amersfoort

Pujadas P, Blanco A, Cavalaro S, Aguado A (2015) Performance-based procedure for the definition of controlled Low-strength mixtures. J Mater Civ Eng 27:06015003. doi:10.1061/(ASCE)MT.1943-5533.0001283

Sanjuan-Delmás D, Petit-Boix A, Gasol C et al (2014) Environmental assessment of different pipelines for drinking water transport and distribution network in small to medium cities: a case from Betanzos, Spain. J Clean Prod 66:588-598. doi:10.1016/j.jclepro.2013.10.055

Spangler MG (1941) The structural design of flexible pipe culverts. Bull. 153. Eng. Exp. Stn, Ames

Swamee PK, Sharma AK (2013) Optimal design of a sewer line using linear programming. Appl Math Model 37:4430-4439. doi:10.1016/j.apm.2012.09.041

Swiss Centre for Life Cycle Inventories (2009) ecoinvent database v3.0. Technical report

The World Bank (2014) Urban population (\% of total). http://data.worldbank.org/indicator/SP.URB.TOTL.IN. ZS. Accessed Jul 2014

Twort AC, Ratnayaka DD, Brandt MJ (2000) Water supply. Butterworth-Heinemann

U.S. Army Corps of Engineers (1998) Engineering and design. Conduits, culverts, and pipes. Engineer Manual 1110-2-2902. Washington, 20314-1000

UN. United Nations. Department of economic and social affairs. Population division (2012) World Urbanization Prospects: The 2011 Revision, CD-ROM Edition

UNE 53331:1997 Plastics. Unplastized poly(vinyl chloride) and high and medium density polyethylene (PE) pipes. Criterion for the assessment of pipes for plastics piping systems with car without pressure under external loads. AENOR, Madrid

Valderrama C, Granados R, Cortina JL, Gasol CM, Josa A (2013) Comparative LCA of sewage sludge valorisation as both fuel and raw material substitute in clinker production. J Clean Prod 51:205-213. doi: 10.1016/j.jclepro.2013.01.026

Venkatesh G, Hammervold J, Brattebø H (2009) Combined MFA-LCA for Analysis of Wastewater Pipeline Networks. J Ind Ecol 13:532-550. doi:10.1111/j.1530-9290.2009.00143.x

Viñolas B (2011) Applications and methodology advances in MIVES multicriteria valorations (Aplicaciones y avances de la metodología MIVES en valoraciones multicriterio). Doctoral Thesis. Universitat Politècnica de Catalunya 